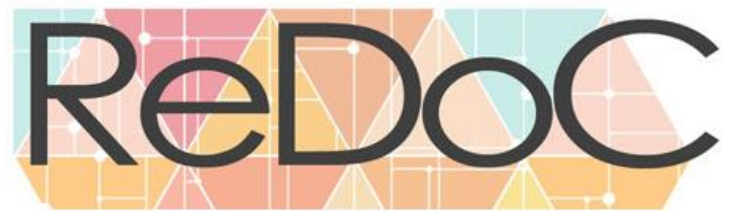

Revista Docência e Cibercultura

\title{
O CORPO TRANSVESTIGÊNERE O CORPO TRAVESTI - NA ARTE
}

\author{
THE TRANSVESTIGENDER BODY \\ THE TRAVESTI BODY IN THE ART
}

Renata Carvalho ${ }^{1}$

\begin{abstract}
RESUMO
Quando o editor da RE-DOC falou da possibilidade de estarmos juntes/xs/as/os enquanto transacademicas junto a/os artivistas, em uma secção artística a primeira pessoa que nos veio à mente, foi a artista, Renata Carvalho*. O motivo foi seu papel nos últimos anos encarnando Jesus Cristo, na peça "O evangelho segundo Jesus, rainha do céu", protagonizado pela atriz e mulher trans/travesti Renata**, em um texto da britânica e também mulher transgênero, Jo Clifford, e que foi traduzido e dirigido por Natalia Mallo. A peça é um monólogo e traz histórias bíblicas sob a perspectiva contemporânea e sob a versão transgênera. A artista Renata Carvalho e sua equipe tiveram seu trabalho cancelado por várias vezes em função de ataques contínuos por parte de alguns membros de grupos religiosos, entre eles, aqueles ligados à Igreja Católica. Para que parte do texto de seu novo espetáculo estivesse presente neste dossiê, esperamos por seu retorno ao Brasil, depois da turnê em apresentações pelo Reino Unido, Europa Central e África. O texto abaixo é o retorno ao nosso pedido por uma composição artística, autoral e inédita para esta revista e segue na integra com a fotografia da autora, produtora e atriz, como parte daquilo que é apresentado em seu trabalho mais recente, o "Manisfeto Transpofágico".
\end{abstract}

PALAVRAS-CHAVE: Jesus Cristo, Rainha do céu; Trans-Artivismorimeira e Resistência Trans

\section{ABSTRACT}

When the editor of RE-DOC told us about the possibility of being together as Trans-academics with the Trans-artivists, in an artistic section, the first person that blow up in our mind was the artist, Renata Carvalho. The reason was her role process in the last years incarnating Jesus Christ in the play "The Gospel According to Jesus, Queen of Heaven", starring as actress and trans/transvesti woman Renata **, in a text written by the British and also transgender woman, Jo Clifford, and which was translated and directed by Natalia Mallo. The play is a monologue and brings biblical stories from the contemporary perspective and under the transgender version. Renata Carvalho and her team had their work canceled several times, due to ongoing attacks by some members of religious groups, including

Submetido em: 08/04/2019

Aceito em: 08/04/2019

Publicado em: 01/06/2019

${ }^{1}$ Atriz, diretora, dramaturga e transpóloga. Fundadora do MONART (Movimento Nacional de Artistas Trans), do "Manifesto Representatividade Trans" e do Coletivo T $\left(1^{\circ}\right.$ Coletivo artístico formado integralmente por artistas Trans em SP). 


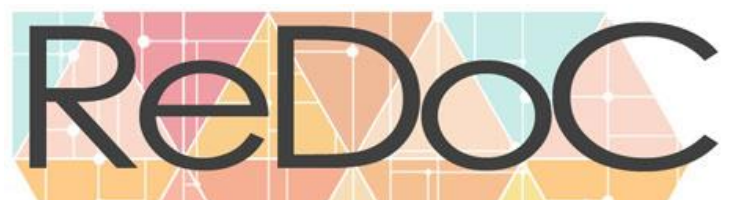

Revista Docência e Cibercultura

those linked to the Catholic Church. As part of the text of her new play to be present in this dossier, we look forward to her return to Brazil, after touring in presentations across the UK, Central Europe and Africa. The text below is the return to our request for an artistic composition, authored and unpublished for this magazine and follows in full with the photograph of the author, producer and actress, as part of what is presented in her most recent work, " The Manisfeto Transpophagic ".

KEYWORDS: Jesus Christ, queen of heaven; Trans-Artvism and Trans Resistence.

\section{TRAVIARCADO: Onde Todos Os Corpos São Natura(lizados)is}

No dia 11 de março de 2019, completamos 2 anos do lançamento do "Manifesto Representatividade Trans", e já podemos sentir mudanças, algumas significativas. Mas e as narrativas que nos rodeiam? E essa construção social e criminalização de nossos corpos que a arte corroborou no imagético do senso comum?

Narrativas dadas em textos romanceados e que nos torna risíveis, caricatas, subjugando as nossas identidades (trans)femininas todo tempo. Como ficam? Narrativas que nos masculinizam, que rechaçam e endemonizam? Do que adiantam?

O corpo transvestigênere, talvez seja o único corpo, que é atacado público e diariamente por parte significativa da Igreja, pela mídia, pelo judiciário, pela medicina, pela arte e ninguém fala nada. Ninguém reclama. Podem fazer qualquer história, de qualquer forma e jeito, pode fazer qualquer vídeo tirando sarro, pode ser peça de teatro, livros, TCCs, mestrados, doutorados, canais no youtube, portais, biografias e até em novelas das 9, que ninguém reclama.

Pode chamar de qualquer coisa, pode erotizar, exotificar, tirar sarro, xingar e deixar nítido a vergonha que todos têm deste corpo.

Pode chama-lo de violento, de bélico, de doente, de anormal.

Pode bater, expulsar de casa e até matar.

Cansamos. Não pode mais não. Que estudo e conhecimento é esse que vocês obtiveram para contar algumas histórias sobre nós? Algumas beiram ao esdrúxulo. Não queremos mais isso não! 


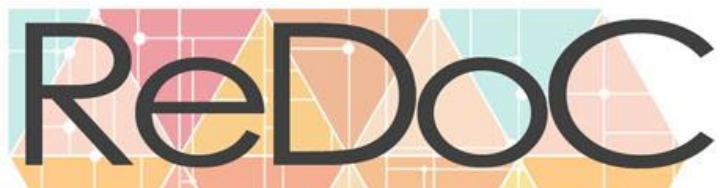

\section{Revista Docência e Cibercultura}

Essas narrativas nos matam todos os dias.

Agora estamos tomando as canetas, os teclados, os lápis de assalto.

Estamos escrevendo nossas histórias, contando outras narrativas, inventando personagens como nós. Nós existimos na nossa Travaturgia.

O meu Teatro pode ser de Rua ou das Ruas.

E minha escrevivência é minha Transcestralidade.

Neste ano (2019), também no dia 20 de março, ao estrear meu novo trabalho: "Manifesto Transpofágico" onde me visto do meu próprio corpo, do meu corpo Travesti, narrando a transcestralidade dele.

O peso dado a esta palavra: Travesti. A este corpo Travesti.

Ela, a palavra, é repetida diversas vezes.

É preciso cansar, desgastá-la.

É preciso falar sobre sem sussurrar, sem cochichar, sem vergonha.

Vamos disseca-la. É preciso.

\section{TRAVESTI. TRAVESTI. TRAVESTI.}

Uma transfofagia da transpologia de uma transpóloga.

Ela digere. Se alimenta.

Precisamos alargar nosso conceito de humanidade. Ele não nos cabe, não nos serve.

Parem os Trans Fakes por 30 anos. Queremos parar de morrer.

Queremos parar de ser suicidadas.

Chega de cidadania precarizada.

A Arte Trans vem como farol na arte cisgênera.

Estamos com as luzes dos postes apontados

Luz. Refletores. Proscênios. $3^{\circ}$ sinal.

A cafetina nos dirigiu.

A arte é e sempre foi democrática.

Pena que os artistas cisgêneros não saibam disso, estamos aqui gritando.

Me dê mais papéis? Folhas. Canetas.

Bem vindes ao Traviarcado onde todes os corpos são naturais. 


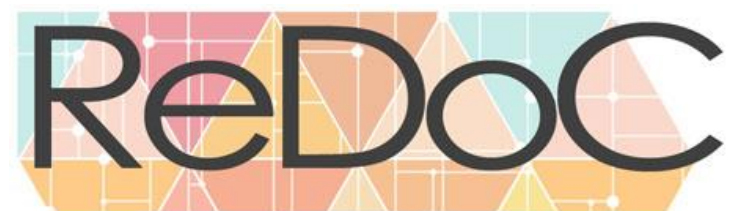

\section{Revista Docência e Cibercultura}

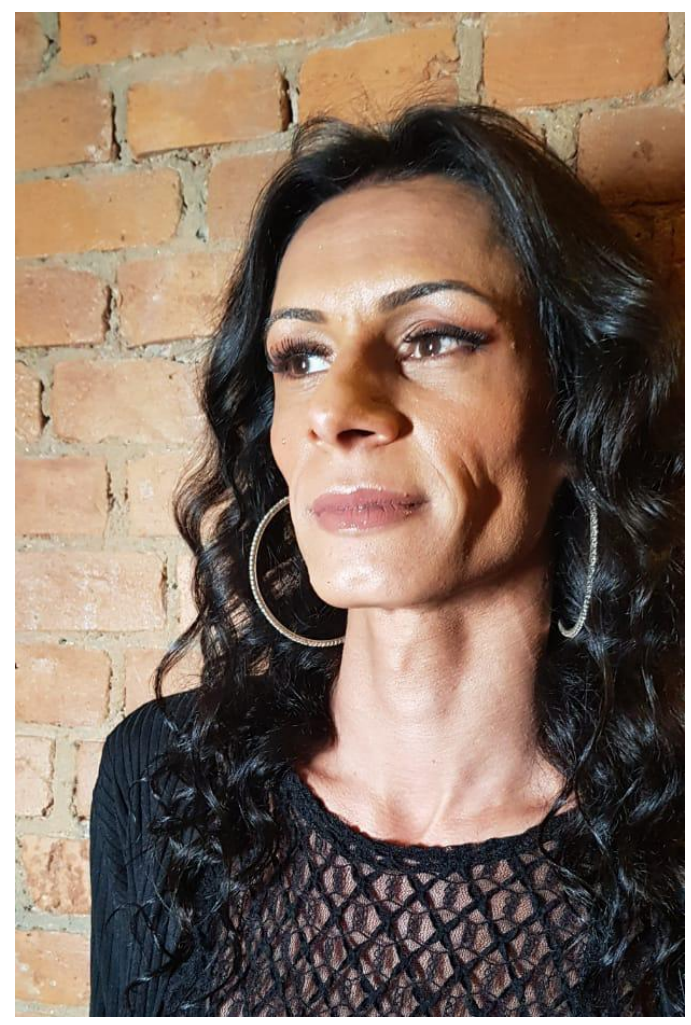

Figura 1. Renata Carvalho, protagonista da peça teatral, "The Gospel According to Jesus Queen of Heaven" Fonte: Imagem enviada pela própria artista.

*Renata Carvalho - Atriz, diretora, dramaturga e transpóloga. Fundadora do MONART (Movimento Nacional de Artistas Trans), do "Manifesto Representatividade Trans" e do Coletivo $\mathrm{T}\left(1^{\circ}\right.$ Coletivo artístico formado integralmente por artistas Trans em SP).

** https://entretenimento.uol.com.br/noticias/redacao/2018/04/05/quem-e-renata-carvalho-aatriz-trans-que-ousou-encarnar-jesus-cristo.htm

\section{REFERÊNCIAS}

CLIFFORD, J. (2018). Excerpt from "The Gospel According to Jesus Queen of Heaven". Journal of Feminist Studies in Religion 34(1), 97-99. Indiana University Press. Retrieved April 9, 2019, from Project MUSE database.

GONÇALVES Jr, Sara Wagner Pimenta. No Mar dos Abandonos: suspiro entre a teoria e prática queer. In: Rebeh-Revista Brasileira de Estudos da Homocultura, 2017. Disponível em: < http://www.revistas.unilab.edu.br/index.php/rebeh/article/view/95/54>. Acesso em $23 / 01 / 2018$ 